\title{
Interaction Mechanism of the Frost Heaving of the Filler and Skeleton Particles in a Micro-Frost-Heaving Filling Material
}

\author{
Xiaoyan Du, Yangsheng Ye, Qianli Zhang, Degou Cai \\ State Key Laboratory for Track Technology of High-Speed Railway, China Academy of Railway Sciences Corporation Limited, Beijing, \\ China
}

\author{
Email address: \\ 466074024@qq.com (Xiaoyan Du)
}

\section{To cite this article:}

Xiaoyan Du, Yangsheng Ye, Qianli Zhang, Degou Cai. Interaction Mechanism of the Frost Heaving of the Filler and Skeleton Particles in a Micro-Frost-Heaving Filling Material. American Journal of Civil Engineering. Vol. 6, No. 4, 2018, pp. 109-117.

doi: 10.11648/j.ajce.20180604.11

Received: June 10, 2018; Accepted: July 16, 2018; Published: September 14, 2018

\begin{abstract}
To address the adverse effects of the frost heaving of subgrades in regions with seasonal frozen soil on the smoothness of high-speed railway tracks, the effects of several factors - including filler, water content and external loading-on a micro-frost-heaving (MFH) filling material were studied through laboratory experiments and theoretical analysis. In addition, the interaction mechanism between the filler and skeleton particles during the frost heaving process was analyzed. The results show the following: The MFH filling material was composed of a coarse-grained skeleton, a filler between skeleton particles and the remaining unfilled voids. When the filling ratio of the filler was 0.25 , the filling material underwent initial macroscopic frost heaving. An overlying load could inhibit the filling material from frost heaving. During the frost heaving process, the volume of coarse skeleton particles with high stiffness remained almost unchanged, whereas the filler expanded in volume and thus filled the remaining voids between skeleton particles and lifted the skeleton particles, resulting in macroscopic frost heaving of the filling material. When their ratio was relatively high, the remaining voids between skeleton particles had a strong absorptivity and weakened the capacity of the filler to lift the skeleton particles. The filler raised the skeleton particles, resulting in an increase in the gaps between them, which in turn facilitated the filling action of the filler. When the skeleton structure was stable, the filling action of the filler was more pronounced. The frost heaving of an MFH filling material is in fact a dynamic equilibrium process between the filling and lifting actions of the filler.
\end{abstract}

Keywords: Frozen Soil Subgrade, Seasonal Frozen Soil, Micro-Frost-Heaving Filling Material, Skeleton Particle, Filler, Frost Heaving Mechanism

\section{Introduction}

Filling materials with a frost heaving ratio, $\eta$, lower than $1 \%$ have excellent compactability, deformation resistance, shear strength and permeability and high filling densities, and they are the main filling materials used in high-speed railway subgrades in cold regions to prevent frost heaving [1]. In this study, these filling materials are referred to as micro-frost-heaving (MFH) filling materials [2]. To facilitate the analysis, an MFH filling material is divided into two parts: the primarily used $7 \mathrm{~mm}$ material and a filler that is composed of particles with a diameter less than or equal to $1.7 \mathrm{~mm}$. For ordinary structures, such as industrial and civil buildings and roads, the frost heaving of MFH filling materials is negligible [3]. However, for high-speed railways, their stringent requirements for structural smoothness do not allow MFH filling materials to undergo frost heaving, which will cause uneven subgrade settling [4]. Currently, studies on the frost heaving mechanism and models of soils focus mainly on fillers-i.e., frost heaving-sensitive soils with a high fine particle content. In addition, studies on relevant classification and frost heaving patterns primarily center on this type of filler [5]. Presently, coarse-grained soils with a low fine particle content (i.e., MFH filling materials) are used in large quantities in high-speed railways. Due to their low $\eta$ value $(<1 \%)$, past studies treated these soils as non-frost heaving soils. In addition, because of their low volume of fine particles, continuous film water and water migration channels cannot be formed in MFH filling materials. As a result, the frost heaving mechanism of ordinary filling 
materials is not applicable to this type of filling material. Given the few available studies concerning the frost heaving characteristics and patterns of MFH filling materials and the significant adverse effects of frost heaving on high-speed railways, it is necessary to study the frost heaving mechanism of MFH filling materials [6, 7].

In this study, through laboratory experiments and theoretical analysis, the effects of several factors: volume of fine particles, continuous film water and water migration channels cannoilling materials used in high-speed railway subgrades in regions with frozen soils and the interaction mechanism of the frost heaving of the filler and skeleton particles during the frost heaving process are investigated [8].

\section{Frost Heaving Experiments}

\subsection{Experimental Setup}

The frost heaving experimental system consists of a sample cell, a constant-temperature chamber, a temperature control system, a temperature monitoring system, a deformation monitoring system, a compression system and a water supply system, as shown in Figure 1 . The sample cell measurements are $15 \mathrm{~cm}($ diameter $) \times 15 \mathrm{~cm}$ (height)

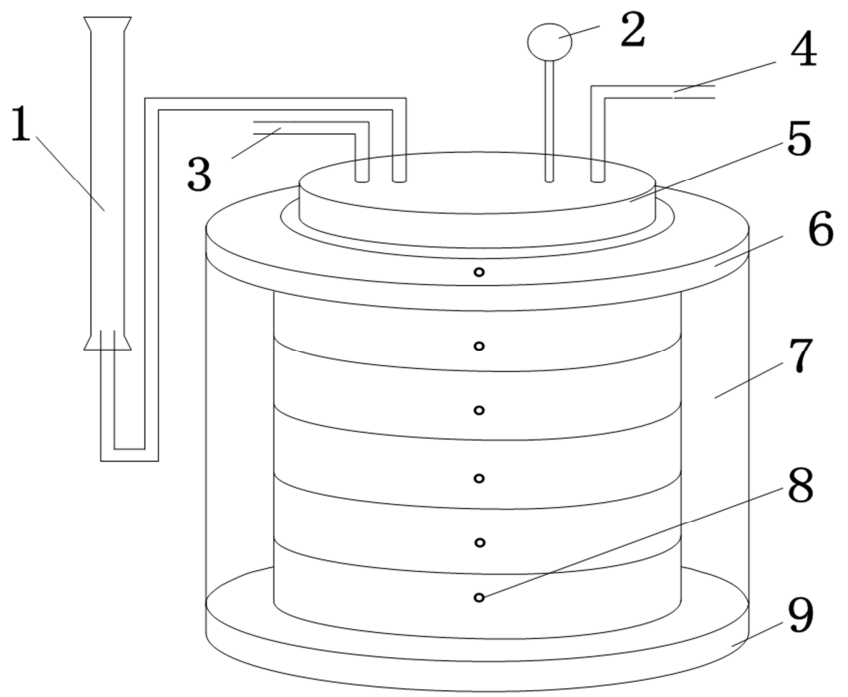

Figure 1. Frost heaving experimental system.

1-water supply system; 2-dial gauge; 3-low-temperature circulating fluid inlet; 4 -low-temperature circulating fluid outlet; 5 - cold bath plate; 6-top plate; 7-thermal insulation material; 8-temperature measuring point for a thermistor; 9 - bottom plate

\subsection{Experimental Method}

Air-dried soil samples were weighed out and mixed with water to the desired water content. Subsequently, each soil sample was divided into five 3-cm-thick layers based on compactness and then placed in the sample cell, which was then placed in the constant-temperature chamber [9]. Thermistor thermometers were placed on the top and bottom plates and the circumferential side of the sample cell. A 5-cm-thick plastic foam sheet was used to wrap the circumferential side of the sample cell for thermal insulation. Two high-precision low-temperature circulating cooling systems were used to control the temperature of each of the top and bottom plates. The deformation of each soil sample was monitored using the dial gauge installed on the top plate. The temperature data for each soil sample were automatically collected by a data acquisition system. The experiment was performed under closed conditions. Each sample was frozen from top to bottom by unidirectional freezing [10]. The entire freezing process lasted $72 \mathrm{~h}$. At the start of the experiment, the temperature of each soil sample was set to approximately $1^{\circ} \mathrm{C}$, which was maintained for $6 \mathrm{~h}$. The temperature of the bottom plate remained unchanged, while the temperature of the top plate was reduced to $-15^{\circ} \mathrm{C}$ within $0.5 \mathrm{~h}$. Consequently, the soil sample was frozen rapidly from the top surface. Afterward, the temperature of the top plate was increased to $-2^{\circ} \mathrm{C}$ and then decreased along a certain gradient every hour. After the experiment was terminated, the soil sample was divided into different layers inside the low-temperature constant-temperature chamber and tested for water content.

\subsection{Experimental Content}

The experimental filling material was collected from the soil used to fill the subgrade of a certain high-speed railway in Northeast China. Table 1 summarizes the gradation of the experimental filling material. The values of the plastic limit, $\omega_{\mathrm{p}}$, and the optimal water content, $\omega_{0}$, of the filler in the filling material were $19.2 \%$ and $13.2 \%$, respectively.

Table 1. Gradation of the experimental filling material.

\begin{tabular}{llll}
\hline $\begin{array}{l}\text { Particle size } \\
\text { range/mm }\end{array}$ & Content/\% & $\begin{array}{l}\text { Particle size } \\
\text { range/mm }\end{array}$ & Content/\% \\
\hline $31.5-45.0$ & 20 & $0.5-1.7$ & 10 \\
$22.4-31.5$ & 10 & $0.1-0.5$ & 9 \\
$7.1-22.4$ & 25 & $0.075-0.1$ & 3 \\
$1.7-7.1$ & 20 & $<0.075$ & 3 \\
\hline
\end{tabular}

To study the effects of water content, filler and external loading on the frost heaving of the MFH filling material, the following frost heaving experiments were performed [11]:

1) Effects of $\omega_{\mathrm{p}}$ and $\omega_{0}$ of the filler on the frost heaving of the MFH filling material

The air-dried filling material was weighed out and mixed with different masses of water. Each mixture was thoroughly mixed. Thus, 30 samples with various initial water contents $(\omega)$ were obtained. Table 2 summarizes the $\omega$ values of the 30 samples. The first 15 samples were used to investigate the effects of $\omega_{\mathrm{p}}$ of the filler on the frost heaving of the MFH filling material, and the remaining 15 samples were used to examine the effects of $\omega_{0}$ of the filler on the frost heaving of the MFH filling material. The mass of each sample was calculated based on a degree of compactness of 0.95 . Each sample was then compacted and placed in the sample cell for the frost heaving experiment. 
Table 2. The initial water content ( $\omega$ ) of the samples.

\begin{tabular}{llllll}
\hline Sample No. & $\boldsymbol{\omega} / \boldsymbol{\%}$ & Sample No. & $\boldsymbol{\omega} / \boldsymbol{\%}$ & Sample No. & $\boldsymbol{\omega} / \boldsymbol{\%}$ \\
\hline 1 & 12.3 & 11 & 19.0 & 21 & 15.6 \\
2 & 14.5 & 12 & 19.6 & 22 & 15.8 \\
3 & 15.1 & 13 & 20.0 & 23 & 16.2 \\
4 & 15.5 & 14 & 20.5 & 24 & 16.3 \\
5 & 15.9 & 15 & 21.3 & 25 & 17.5 \\
6 & 16.0 & 16 & 13.3 & 26 & 17.8 \\
7 & 16.5 & 17 & 14.3 & 27 & 18.0 \\
8 & 18.0 & 18 & 14.4 & 28 & 19.1 \\
9 & 18.5 & 19 & 14.7 & 29 & 19.4 \\
10 & 18.8 & 20 & 15.5 & 30 & 21.7 \\
\hline
\end{tabular}

2) Effects of volumetric water content, $\omega_{V}$, on the frost heaving of the MFH filling material

The air-dried filling material was weighed out and mixed with different masses of water. Each mixture was thoroughly mixed. Thus, 15 samples with different $\omega_{V}$ values were obtained. Table 3 summarizes the $\omega_{V}$ values of the 15 samples. The mass of each sample was calculated based on a degree of compactness of 0.95 . Each sample was then compacted and placed in the sample cell for the frost heaving experiment.

Table 3. The volumetric water content $\left(\omega_{V}\right)$ of the samples.

\begin{tabular}{llllll}
\hline Sample No. & $\omega_{V} / \%$ & Sample No. & $\omega_{V} / \%$ & Sample No. & $\omega_{V} / \%$ \\
\hline 1 & 5.83 & 6 & 11.34 & 11 & 15.80 \\
2 & 7.02 & 7 & 11.85 & 12 & 16.04 \\
3 & 8.30 & 8 & 13.17 & 13 & 16.57 \\
4 & 9.60 & 9 & 14.48 & 14 & 17.49 \\
5 & 11.07 & 10 & 15.27 & 15 & 18.21 \\
\hline
\end{tabular}

3) Effects of the filler content and the volumetric filling ratio of the filler, $S$, on the frost heaving of the MFH filling material

A sample of the filling material with a desired filler content can be prepared by adding the filler at a corresponding proportion to a certain mass of the air-dried filling material and thoroughly mixing the resulting mixture. For each filling material, $S$ was calculated using the following equation:

$$
S=\frac{1-V_{1}}{V_{2}} \times 100 \%
$$

where:

$$
V_{1}=\frac{M_{1}}{\gamma_{1}} \quad V_{2}=\frac{M_{2}}{\gamma_{2}}
$$

$V_{1}$ is the volume fraction of skeleton particles in the filling material; $V_{2}$ is the volume fraction of the filler in the filling material; $M_{1}$ is the mass of skeleton particles per unit volume of the filling material; $\gamma_{1}$ is the dry density of skeleton particles corresponding to the degree of compactness of the filling material; $M_{2}$ is the filler mass per unit volume of the filling material; and $\gamma_{2}$ is the dry density of the filler corresponding to the degree of compactness of the filling material.

A total of 15 samples were prepared for this experiment. Table 4 summarizes the filler content and $S$ of each sample. Each sample had a $\omega$ of $15 \%$ and a degree of compactness of 0.95 when subjected to the frost heaving experiment.

\begin{tabular}{|c|c|c|c|c|c|}
\hline Sample number & Filler content $/ \%$ & $S$ & Sample number & Filler content $/ \%$ & $S$ \\
\hline 1 & 1.0 & 0.056 & 9 & 6.0 & 0.445 \\
\hline 2 & 2.0 & 0.118 & 10 & 9.0 & 0.465 \\
\hline 3 & 2.5 & 0.198 & 11 & 11.0 & 0.529 \\
\hline 4 & 2.8 & 0.272 & 12 & 16.0 & 0.532 \\
\hline 5 & 3.0 & 0.316 & 13 & 18.0 & 0.606 \\
\hline 6 & 3.2 & 0.334 & 14 & 40.0 & 0.859 \\
\hline 7 & 5.0 & 0.363 & 15 & 45.0 & 0.928 \\
\hline 8 & 5.5 & 0.381 & & & \\
\hline
\end{tabular}

Table 4. Filler content and volumetric filling ratio (S) of each sample.

4) Effects of the frost heaving of the filler on the frost heaving of the MFH filling material

For each of the 15 filling materials with various filler contents in Table 4 (all had $\omega$ of $15 \%$ and a degree of compactness of 0.95 ), two separate frost heaving experiments were performed on it and its filler [12].

5) Effects of an overlying load on the frost heaving of the MFH filling material

A sample of the filling material with a filler content of $10 \%$ and a $\omega$ of $15 \%$ was prepared. This sample was then subjected to a frost heaving experiment while overlying loads of 5, 10, 20, 30, 40, 55, 65 and $80 \mathrm{kPa}$ were applied. Figure 2 shows the loading system used in the frost heaving experiment.

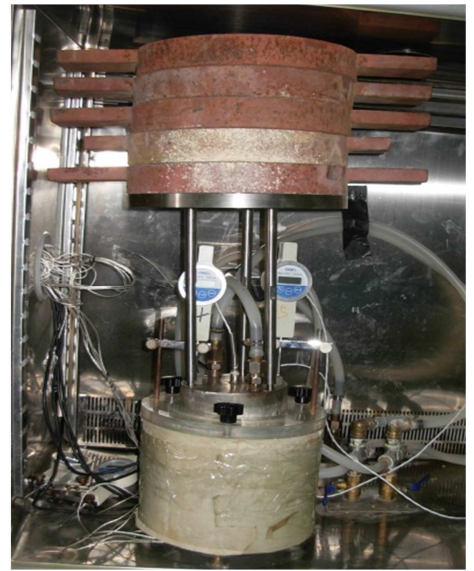

Figure 2. Loading system used in the frost heaving experiment. 


\section{Analysis of the Experimental Results}

The $\eta$ value of an MFH filling material was calculated using the following equation:

$$
\eta=\frac{\Delta h}{H_{f}} \times 100 \%
$$

where $\Delta h$ is the total amount of frost heaving of the sample $(\mathrm{mm})$, and $H_{f}$ is the depth of freezing (excluding the amount of frost heaving) (mm).

\subsection{Effects of Water Content on the Frost Heaving of the MFH Filling Material}

\subsubsection{Relationships Between $\omega_{p}$ and $\omega_{o}$ of the Filler and the Frost Heaving of the MFH Filling Material}

Figure 3 shows the relationship between $\left(\omega-\omega_{\mathrm{p}}\right)$ and $\eta$ of the filling material. Figure 4 shows the relationship between $\left(\omega-\omega_{o}\right)$ and $\eta$ of the filling material. As demonstrated in Figures 3 and 4 , when $\omega \leq \omega_{p}+2 \%$ or $\omega \leq \omega_{o}+4.6 \%, \eta<1 \%$; however, as the value of $\omega$ continued to increase, the $\eta$ value of the filling material increased significantly.

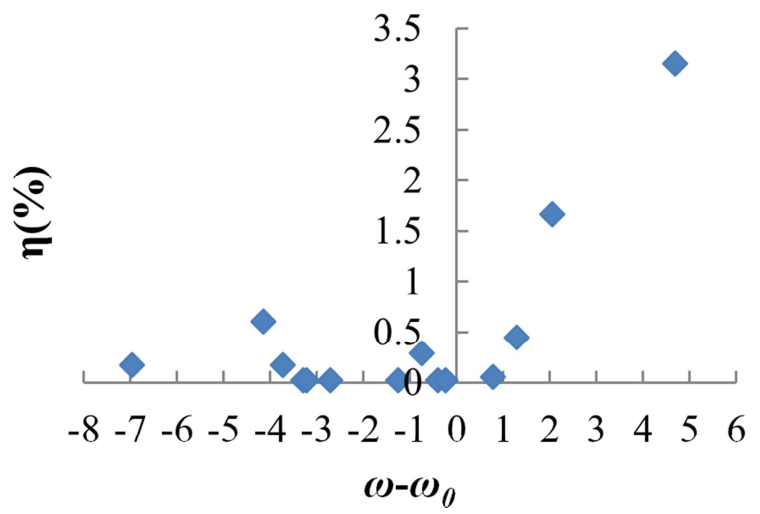

Figure 3. Relationship between the plastic limit $\left(\omega_{p}\right)$ of the filler and the frost heaving of the filling material.

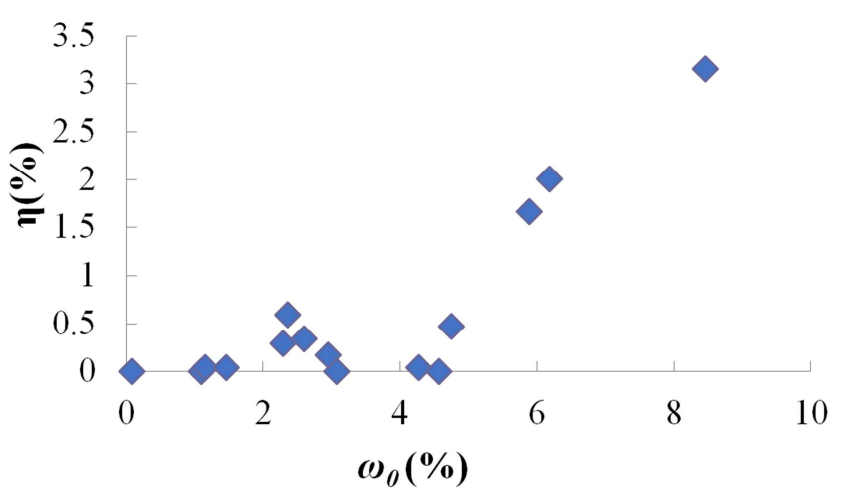

Figure 4. Relationship between the optimal water content $\left(\omega_{o}\right)$ of the filler and the frost heaving of the filling material.

\subsubsection{Relationship Between the Volumetric Water Content $\left(\omega_{V}\right)$ and $\eta$ of the MFH Filling Material}

Figure 5 shows the $\eta$ values of samples with various $\omega_{V}$. As demonstrated in Figure 5, when $\omega_{V} \leq 13 \%$, the $\eta$ value of the filling material was insensitive to the increase in $\omega_{v}$; when $\omega_{v}>13 \%$, the amount of frost heaving of the filling material increased significantly as the value of $\omega_{v}$ increased.

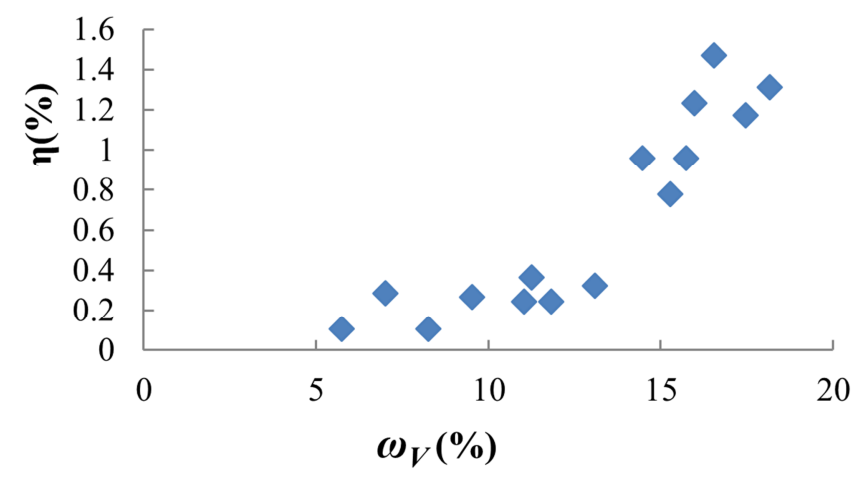

Figure 5. Relationship between $\eta$ and $\omega_{V}$ of the filling material.

\subsection{Effects of the Filler on the Frost Heaving of the MFH Filling Material}

\subsubsection{Relationships Between the Filler Content and Volumetric Filling Ratio (S) and the Frost Heaving Rate ( $\eta$ ) of the MFH Filling Material}

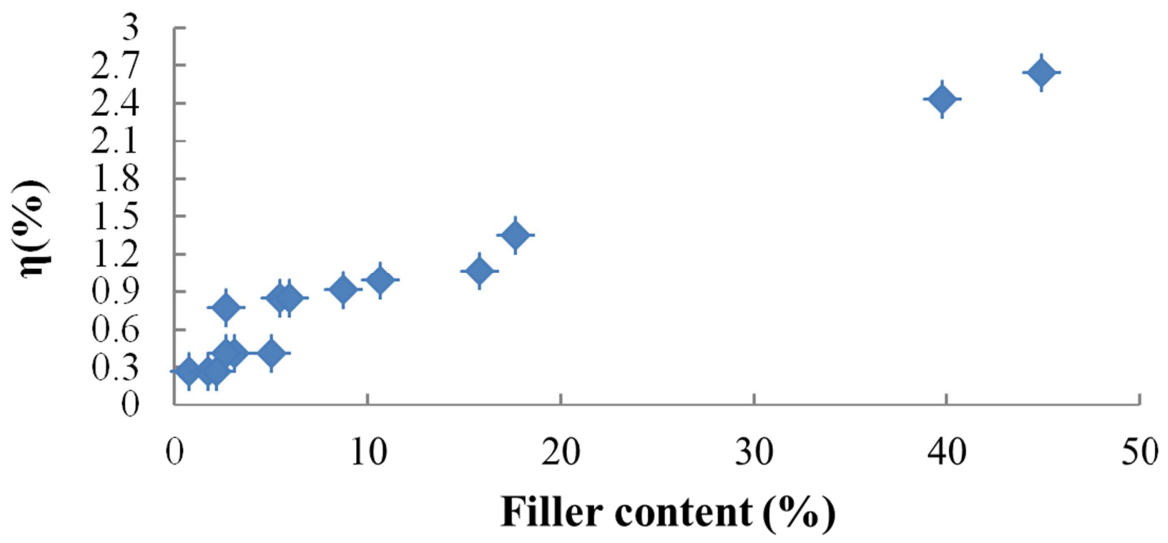

Figure 6. Relationship between the filler content and $\eta$ of the MFH filling material. 
Figure 6 shows the $\eta$ values of MFH filling materials with various filler contents. As demonstrated in Figure 6, the frost heaving capacity of the filling material gradually increased as the filler content increased. When the filler content was less than $3 \%, \eta \approx 0.2 \%$; when the filler content was less than $15 \%$, $\eta<1.0 \%$; and when the filler content was greater than $15 \%$, the frost heaving sensitivity of the filling material increased significantly as the filler content increased.

Figure 7 shows the $\eta$ values of MFH filling materials with various $S$ values. As demonstrated in Figure 7, when $S<0.18$, $\eta<0.2 \%$; when $S<0.25, \eta<0.5 \%$, suggesting that the frost heaving of the filling material was insensitive to the increase in $S$; when $S>0.25, \eta$ increased significantly, and the frost heaving sensitivity of the filling material increased as $S$ increased; when $S<0.37, \eta<1.0 \%$.

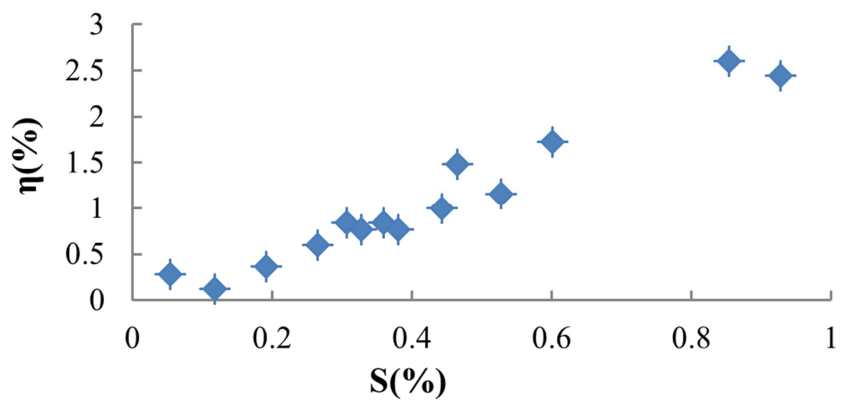

Figure 7. Relationship between the volumetric filling ratio (S) and the frost heaving rate ( $\eta$ ) of the MFH filling material.

\subsubsection{Relationship Between the Amounts of Frost Heaving of the Filler and the Filling Material}

Based on the experimental results, a plot depicting the relationship between the amounts of frost heaving of the filler and each filling material was produced (Figure 8). As demonstrated in Figure 8, when the amount of frost heaving of the filler was less than $25 \mathrm{~cm}^{3}$, the MFH filling material did not undergo frost heaving. Under this condition, the filler filled the voids as a result of frost heaving, which did not induce the macroscopic frost heaving of the filling material. When the amount of frost heaving of the filler was greater than $25 \mathrm{~cm}^{3}$, the MFH filling material underwent frost heaving, and its amount of frost heaving increased significantly as the amount of frost heaving of the filler increased.

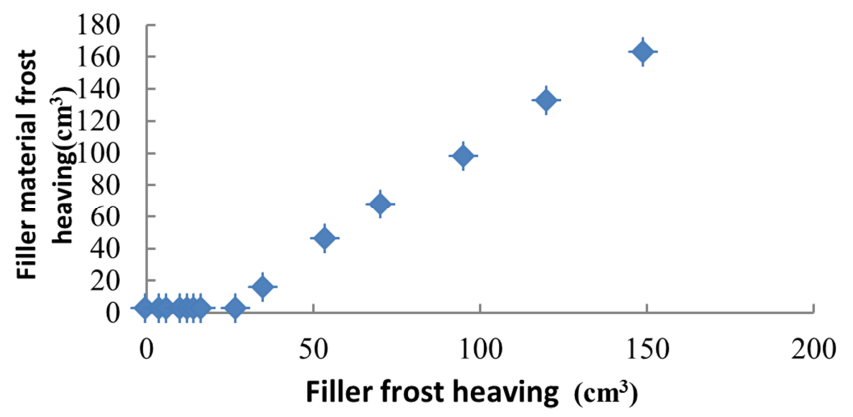

Figure 8. Relationship between the amount of frost heaving of the filler and the filling material.

\subsection{Relationship Between the Overlying Load and the Frost Heaving of the MFH Filling Material}

An overlying load affects the frost heaving capacity of an MFH filling material in two ways: an increase in the external constraint results in a decrease in the freezing point of the filling material, and the water inside the filling material is redistributed as a result of the action of the overlying load [13]. Figure 9 shows the $\eta$ values of the MFH filling material under various overlying loads. As demonstrated in Figure 9, the $\eta$ value of the MFH filling material was exponentially related to the overlying load and gradually decreased as the overlying load increased.

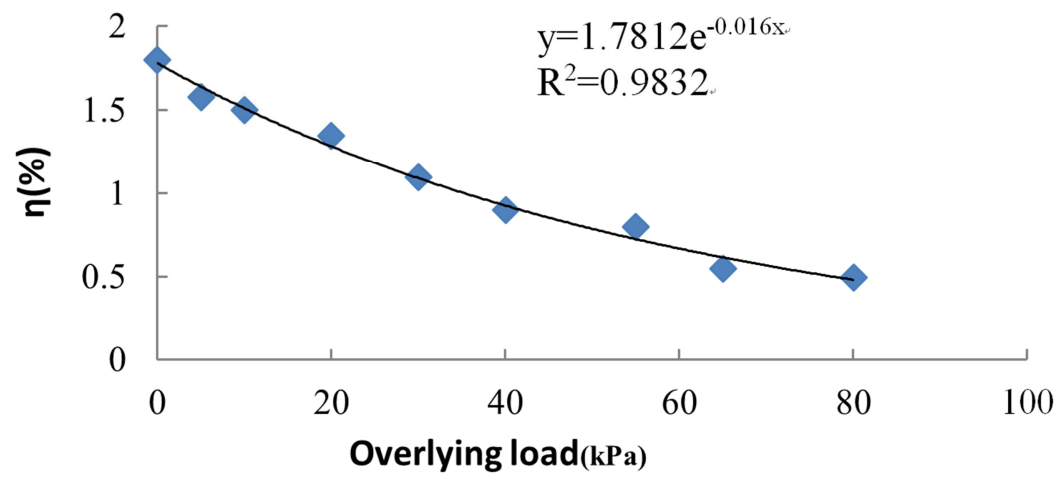

Figure 9. Relationship between the overlying load and $\eta$ of the MFH filling material.

\section{Frost Heaving Mechanism of MFH Filling Materials}

\subsection{Interaction between the Frost Heaving Filler and the Skeleton Particles}

An MFH filling material is composed of coarse particles and a small amount of fine-grained filler [14]. Structurally, an MFH filling material can be divided into skeleton particles and a filler. The filler is distributed between skeleton particles and fills the voids between them. When the external constraint is weak, filler particles undergo frost heaving. Consequently, skeleton particles are lifted, and micro-displacement occurs between adjacent skeleton particles, resulting in an 
enlargement of the voids between skeleton particles, which can facilitate the filling of the voids. When the external constraint is strong, compressive swelling occurs between skeleton particles and the filler, which inhibits the frost heaving of the MFH filling material [15]. When frozen, the volumetric expansion of the filler exerts two actions: it fills the remaining voids and intensifies internal absorption by frost heaving, and it lifts skeleton particles, resulting in the occurrence of macroscopic frost heaving. The frost heaving of an MFH filling material is a dynamic equilibrium process between the lifting and filling actions. Figure 10 shows the interaction between the filler and skeleton particles.

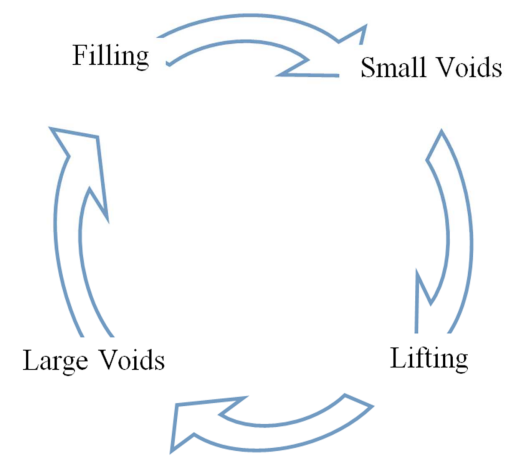

Figure 10. Interaction between the filler and the skeleton particles.

\subsection{Analysis of the Degree of Filling Compactness of MFH Filling Materials}

The proportions of particles of various sizes directly determine the structural type of an MFH filling material [16]. Generally, there are three structural types of MFH filling materials: suspended-dense, skeleton-dense and skeleton-void structures. These structures are shown in Figure 11. When the proportion of filler particles is low, not all voids can be filled, and the MFH filling material has a skeleton-pore structure. As the proportion of filler particles increases, when the voids between skeleton particles are filled only by filler particles, the MFH filling material transitions into a skeleton-dense structure. The proportion of coarse particles decreases as the proportion of filler particles continues to increase. When the originally formed skeleton is pressed open by filler particles, the MFH filling material transitions into a suspended-dense structure.

The compactness of an MFH filling material is directly related to its structural type. For an MFH filling material, the extent to which the voids between skeleton particles are filled is determined by its volumetric filling ratio [2]. In this study, only the scenario in which the voids between skeleton particles are filled by filler particles is analyzed.
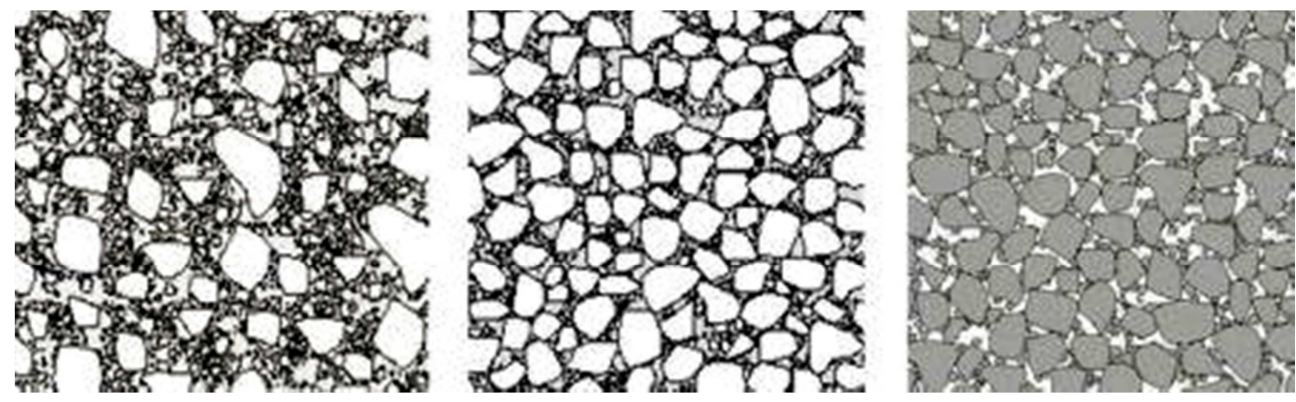

(a) Suspended-dense structure; (b) skeleton-dense structure; (c) skeleton-void structure

Figure 11. Structural types of filling materials.

For a certain degree of compactness, the dry distribution density, $\rho_{\text {fmaxx }}$, of particles with a diameter greater than $x$ in a filling material can be calculated using the following equation:

$$
\rho_{\text {fmaxx }}=\rho_{\text {dmaxx }} \times \rho_{x}
$$

where $\rho_{\text {dmaxx }}$ is the maximal dry density of particles with a diameter greater than $x$ in the sample under the same compaction standard, and $\rho_{x}$ is the percentage of particles in the sample with a diameter greater than $x(\%)$.

Here, $D_{c}$ is defined as the boundary particle size separating filler particles from skeleton particles. Under the same compaction standard, when the diameter $x$ of the filling material is less than or equal to $D_{c}$, the dry distribution density of particles with a diameter less than or equal to $x$ (i.e., the remaining particles) in the filling material is the same as that of particles with a diameter greater than $x$-i.e., $\rho_{\text {fmaxx }}=\rho_{\text {dmaxx }}$. When $x>D_{c}$, particles with a diameter greater than $x$ in the filling material are separated from one another; they are distributed in suspension. Under this condition, $\rho_{\text {fmaxx }}<\rho_{\text {dmaxx }}$. Therefore, $D_{c}$ is the particle size when $\rho_{\text {fmaxx }}<\rho_{\text {dmaxx }}$ occurs for the first time as $x$ increases. The percentage content, $\beta_{i}$, of particles with a diameter smaller than $D_{c}$ is:

$$
\beta_{i}=\frac{\rho_{i, d \max }-\rho_{i, \text { fmax }}}{\rho_{i, d \max }}
$$

where $\rho_{\mathrm{i}, \mathrm{dmax}}$ is the maximal dry density of the filling material after the $i^{\text {th }}$ iteration of removal of the smallest particle fraction, and $\rho_{i, f \max }$ is the maximal dry distribution density of the filling material after the $i^{\text {th }}$ iteration of removal of the smallest particle fraction.

Under ideal conditions, when the degrees of compactness are the same, and $\rho_{\text {fmaxx }}=\rho_{\text {dmaxx }}$, the state of the remaining particles in the skeleton of the filling material is equivalent to a densely compacted state. Considering the effects of experimental errors, and to maintain consistency with the 
allowable error for the parallel experiment on the maximal dry density of the filling material, the error range can be set to $3 \%$. In other words, when $\beta_{i} \leq 3 \%$, the filling material has a skeleton-dense structure. Figure 12 shows the $\rho_{\text {fmaxx }}$ and $\rho_{\text {dmaxx }}$ curves of a filling material with a skeleton-dense structure. As demonstrated in Figure 12, $D_{c}$ is the point where the two curves intersect. When $\beta_{\mathrm{i}}>3 \%$, the particles, excluding the $i^{\text {th }}$ particle fraction, are suspended in the skeleton-i.e., the filling material has a suspended-dense structure. Figure 13 shows the $\rho_{\text {fmaxx }}$ and $\rho_{\text {dmaxx }}$ curves of a filling material with a suspended-dense structure. In this structure, all particles in the filling material are skeleton particles.

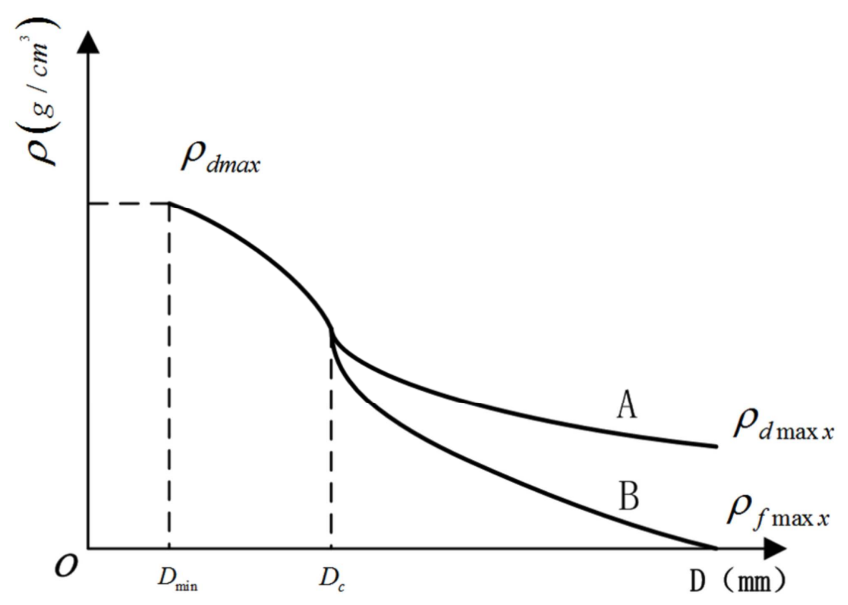

Figure 12. $\rho_{\text {fmaxx }}$ and $\rho_{\text {dmaxx }}$ curves of a filling material with a skeleton-dense structure.

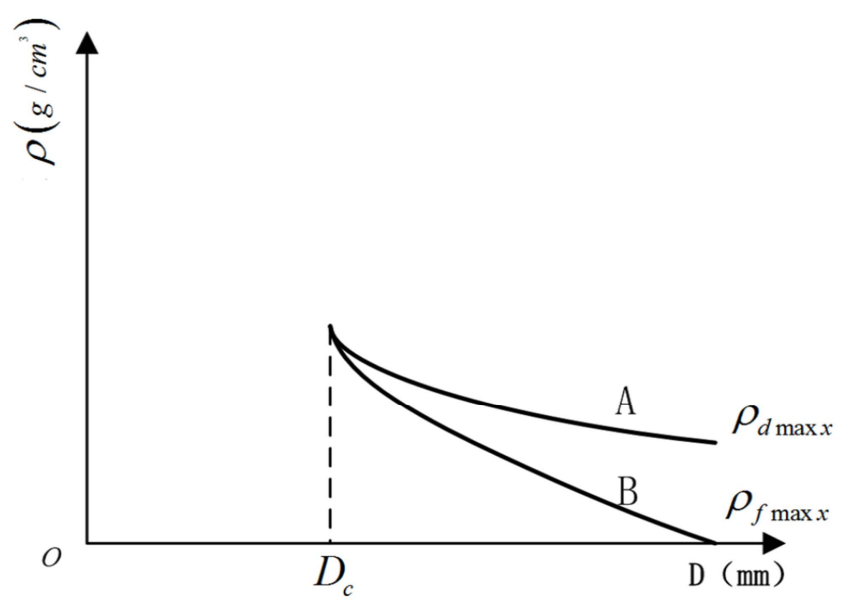

Figure 13. $\rho_{\text {fmaxx }}$ and $\rho_{\text {dmaxx }}$ curves of a filling material with a suspended-dense structure.

After $D_{c}$ is determined through analysis, the dry filling density, $\rho_{t}$, of the filler in the voids of the filling material can be determined:

$$
\rho_{t}=\rho_{d \max } \times\left(1-p_{D_{c}}\right) / n_{g}
$$

where: $n_{g}=1-\rho_{d \max } \times p_{D_{c}} / \rho_{a g}$

$\rho_{d \max }$ is the maximal dry density of the filler in the filling material $\left(\mathrm{g} / \mathrm{cm}^{3}\right) ; \rho_{D c}$ is the percentage of skeleton particles in the filling material $(\%) ; n_{\mathrm{g}}$ is the void ratio when the filler is in a dry-dense state; and $\rho_{a \mathrm{~g}}$ is the gross volume density of skeleton particles $\left(\mathrm{g} / \mathrm{cm}^{3}\right)$.

Let

$$
\alpha_{i}=\left(\rho_{t \max }^{\prime}-\rho_{t}^{\prime}\right) / \rho_{d \max }^{\prime}
$$

where $\rho_{\text {tmax }}^{\prime}$ is the maximal dry density of the filler in the voids of the filling material at a certain time $\left(\mathrm{g} / \mathrm{cm}^{3}\right) ; \rho_{t}^{\prime}$ is the dry filling density of the filler in the voids of the filling material at a certain time $\left(\mathrm{g} / \mathrm{cm}^{3}\right)$; and $\rho_{d \max }^{\prime}$ is the maximal dry density of the filler in the filling material at a certain time $\left(\mathrm{g} / \mathrm{cm}^{3}\right)$.

For the same degree of compactness, the density of the filler in the voids of the skeleton can be determined by analyzing the relationship between $\rho^{\prime}{ }_{\text {tmax }}$ and $\rho_{t}^{\prime}$ of the filler. When the voids of the skeleton are densely filled by the filler, $\rho^{\prime}{ }_{t \max }=\rho_{t}^{\prime}$, and the error range is $3 \%$. When $a_{i} \leq 3 \%$, the filling material has a skeleton-dense structure. When $a_{i}>3 \%$, the filling material has a skeleton-void structure. $\rho_{\text {tmax }}$ is far greater than $\rho_{t}$, suggesting that filler particles are in a free state in the voids between skeleton particles in the filling material.

\subsection{Classification of the Structural Types of MFH Filling Materials}

The filling and lifting behaviors of an MFH filling material are related to its internal structural characteristics. MFH filling materials of the three structural types differ significantly in their frost heaving capacity. As the main filling material in the surface layer of high-speed railway subgrades, graded crushed stones must ensure long-term stable operation of the subgrade structure under dynamic loading from trains and prevent the subgrade structure from significant continuous cumulative plastic deformation [17]. Therefore, the gradation range for subgrade filling materials is definitively stipulated in the Code for Design of High-Speed Railways (TB 10621-2014). However, compacted graded crushed stones with various particle size gradations within the stipulated range exhibit various structural types. The analytical results show that the skeleton-dense structure is the optimal structural type after compaction. The skeleton-void and suspended-dense structures should be avoided because cumulative plastic deformation will occur in these two structures after the long-term action of the climatic environment and dynamic loading from trains and will affect the smoothness of the railway tracks. In addition, when pore water in water-rich regions is not drained in a timely fashion, the structural strength of the soil mass will decrease due to an unfavorable structure [18]. When determining the gradation of filling materials for high-speed railway subgrades in cold regions, the skeleton-void structure, which has a small proportion of fine particles, can be selected to facilitate drainage of water and prevent freezing.

When the gradation of an MFH filling material in the surface layer of a high-speed railway subgrade changes from 
the upper limit stipulated in the design code to the lower limit, the filler content of the MFH filling material gradually decreases. When the gradation of an MFH filling material is between the upper limit and the median value, the MFH filling material has a graded suspended-dense structure. When the gradation of an MFH filling material changes from the median value to the lower limit, there are three structural types in the MFH filling material: a suspended-dense structure in the region near the median value, a skeleton-dense structure in the region between the median value and the lower limit, and a skeleton-void structure in the region near the lower limit. Figure 14 shows an approximate range classification of the structural types of MFH filling materials.

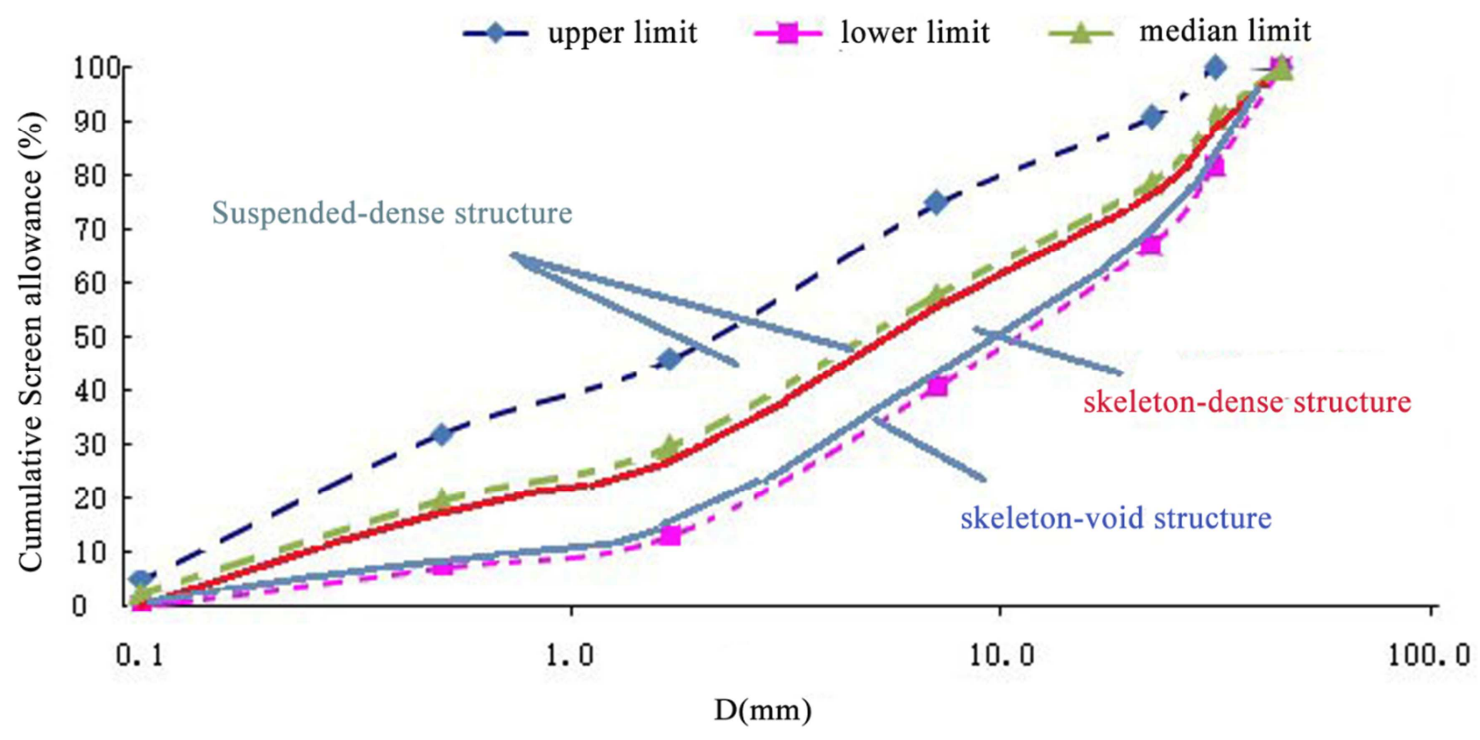

Figure 14. Range classification of graded structural types of filling materials for the surface layer of high-speed railway subgrades.

\section{Conclusion}

(1) As the filler content decreases, the $\eta$ value of the MFH filling material gradually decreases. However, even when the filling material contains a low fine particle content, it may still undergo frost heaving deformation in low-temperature conditions. An overlying load can, to a certain extent, inhibit the frost heaving of the MFH filling material.

(2) As the amount of frost heaving of the filler increases, the amount of frost heaving of the MFH filling material also increases. When $S<0.25$, an increase in the filler content does not significantly affect the frost heaving of the MFH filling material. Under this condition, as a result of frost heaving, the filler fills the voids between skeleton particles without causing macroscopic frost heaving of the MFH filling material. When $S>0.25, \eta$ of the MFH filling material increases significantly as $S$ increases.

(3) When the external constraint is strong, the frost heaving of the filler is mainly reflected by the filling of voids between skeleton particles. When the external constraint is weak, the expansion of the filler caused by frost heaving results in the lifting of the skeleton and, thus, the macroscopic frost heaving of an MFH filling material. After being lifted, absorption inside the skeleton structure increases, which is favorable to the development of the filling action of the filler. The frost heaving of an MFH filling material is a dynamic equilibrium process between its lifting and filling actions.

(4) The internal structural characteristics of an MFH filling material will affect its filling and lifting actions. The proportions of particles of various sizes are directly related to the structural type of MFH filling material. There are three structural types of MFH filling materials: a skeleton-void structure, a skeleton-dense structure, and a suspended-dense structure.

\section{Acknowledgements}

This study was financially supported by the Industrial Service Technology Innovation Program (2016YJ307) of the China Academy of Railway Sciences and the Scientific and Technological Research Development Program (HJKL-05, 2017G06) of Taiyuan Railway Bureau.

\section{References}

[1] Y. S. Ye (2004). Railway subgrade filling material classification. China Railway Science. pp. 35-41.

[2] X. Du (2015). A Study on the Frost Heave Mechanism of Micro-Frost-Heave Filling based on The Interaction of Frost Heave of Filling Material and Coarse Particles Skeleton. Beijing: China Academy of Railway Sciences.

[3] Y. S. Ye, Q. L. Zhang (2016). Study on Frost Heaving Law of filling featuring micro frost heaving for high speed railway subgrade. China Railway Science. pp. 82-85.

[4] Y. Guo (2016). Study on the effect of subgrade Frost Heaving on the deformation properties of track structure and ITS vehicle dynamic behavior in high speed railway. Master Degree Thesis. Southwest Jiao Tong University. 
[5] J. F. Zheng, S. P. Zhao, W. Ma, et al. (2009). Study of the effect of freezing on frozen soil specimen preparation. Journal of Glaciology and Geocryology. Vol. 31, pp. 130-138.

[6] Y. P. Liu (2016). Treatment technology of subgrade Frost Heaving for high speed railway in severe cold area. Railway Engineering. pp. 92-97.

[7] C. Y. Zhang (2018). Research on the Frost-heave performances of filling material consisted of coarse grained soil for highspeed railway subgrade. Journal of Railway Engineering Society.

[8] J. Y. Leng (2015). Experimental research of the subgrade padding Frost Heaving of high-speed railway. Journal of Glaciology and Geocryology. Vol. 37, pp. 440-445.

[9] J. Lan (2016). Experimental study on Frost Heave performance improvement of coarse grain filling in high speed railway subgrade. China Railway Science. pp. 105.

[10] Y. Tian, J. Liu and L. Peng (2010). Experimental study on frost action of fine-grained soils under dynamic and static loads. Chinese Journal of Geotechnical Engineering. Vol. 32, pp. $1882-1888$

[11] C. Wang, R. Zhang, X. Zhao, et al. (2014). Frost heaving monitoring system and frost heaving rules for the high-speed railway embankment in the seasonally frozen soil regions. Journal of Glaciology and Geocryology. Vol. 36, pp. 962-968.
[12] H. Zhao, H. Yan, Q. Zhang, et al. (2014). Study on frost-heave performances of filling material consisted of coarse grained soils for subgrade bed in season frozen region. Railway Engineering. pp. 92-94.

[13] L. Jiang, L. Wang, X. Zhang, et al. (2009). Experiment on normal frozen-heave force of low liquid-limit clay of highway roadbed in seasonal frost region. China Journal of Highway and Transport. Vol. 2.

[14] X. Du, Y. Ye, Q. Zhang, et al. (2016). Proposal to apply anti-frost filling material of high speed railway subgrade in seasonal frozen soil region. Railway Engineering. pp. 43-46.

[15] G. T. Zhao (2017). Distribution features of fine-grain in filling material of High - speed railway subgrade and its impact on Frost Heaving. RNAL of Railway Engineering Society.

[16] M. L. Zhao (2016). Research on Anti-Frost design for railway subgrade in seasonal Frozen earth area. China Railway Economic Planning and Research Institute. pp. 42-49.

[17] Q. Zhang, Z. Han, B. Lü (2005). Analysis and design method of subgrade bed in high speed railway. China Railway Science. pp. 55-59.

[18] Z. Q. Wang (2017). Study on the Frost Heaving behavior and strength of coarse-grained fillings form high-speed railway sungrade in cold region. Master Degree Thesis. Beijing Jiao Tong University. 